\title{
Pemberdayaan Mustahiq BAZNAS Kabupaten Sukabumi Melalui Program Bangkit Usaha Mikro Berbasis Masjid Desa Peradaban Zakat (BUMI DPZ)
}

\author{
Husnul Khatimah $^{1 *)}$, Nuradi ${ }^{2)}$ \\ ${ }^{1,2}$ Sekolah Tinggi Ilmu Bahasa Arab Ar Raayah Sukabumi \\ *Email korespondensi: husnul. khatimah@araayah.ac.id
}

\begin{abstract}
BAZNAS Sukabumi Regency has a superior program named Micro Enterprise/ Bangkit Usaha Mikro (BUMI) that based on Zakat Civilization's Village/ Desa Peradaban Zakat (DPZ) of mosque which is carried out following local socio-cultural community factors, by spiritual and material empowerment at the same time in accordance with its motto ngaji (ruhani) or spiritual empowerment and ngejo (rupiah) or material empowerment. This study aims to determine the success level of the mustahiq empowerment program through the BUMI DPZ program in BAZNAS, Sukabumi Regency. The research that will be used is a survey research by conducting interviews and using a questionnaire, with descriptive analysis methods and qualitative approaches, in the form of collecting facts in the field from interviews in the form of questionnaires to respondents. The results show that the success level of the BUMI DPZ BAZNAS program in Sukabumi Regency in terms of rupiah development is still low due to various obstacles, including the mentality of the assisted residents (mustahiq) who are still in consumptive orientation is still quite difficult to changing to be a productive one and already familiar with the usury system coupled with the limited number of assistants who at the same time have to deal with other institutions that offer assistance programs with interest-bearing loans, even though assistants play a major role in changing the people's mindset as well as agents of change to create empowered community conditions, while in terms of ruhiyah development it can be said to be successful with community assistants activeness to follow routine recitation held by a companion and have routinely issued
\end{abstract}

Abstract

Keywords : Empowerment, Mustahiq, BUMI DPZ, BAZNAS

Saran sitasi: Khatimah, H., \& Nuradi. (2021). Pemberdayaan Mustahiq BAZNAS Kabupaten Sukabumi Melalui Program Bangkit Usaha Mikro Berbasis Masjid Desa Peradaban Zakat (BUMI DPZ). Jurnal Ilmiah Ekonomi Islam, 7(01), 23-33. doi: http://dx.doi.org/10.29040/jiei.v7i1.1594

DOI: http://dx.doi.org/10.29040/jiei.v7i1.1594

\section{PENDAHULUAN}

Ahsan (2009) mengungkapkan bahwa Indonesia sebagai negara berkembang memiliki banyak masalah dalam bidang perekonomian, salah satunya adalah masalah kemiskinan yang kondisinya masih sangat memprihatinkan, pernyataan ini selaras dengan yang dikemukakan oleh (Efendi, 2017) dan (Farida, 2019). Hal ini dapat terlihat pada data kinerja penanggulangan kemiskinan nasional yang mengalami pasang surut dalam beberapa tahun terakhir, terlebih setelah berakhirnya era commodity booms (tingginya harga komoditas) di antaranya adalah ketidakstabilan tingkat harga dan perluasan lapangan pekerjaan masih terus menjadi kebijakan utama pemerintah dalam menanggulangi persoalan kemiskinan yang masih menjadi momok di negeri ini, sebagaimana dikemukakan (Wibisono, 2017) dan (Widiastuti \& Rosyidi, 2015).

Riyadi (2014) mengemukakan bahwa dalam upaya mengentaskan masalah kemiskinan Islam telah memberikan solusi yang telah Allah Subhanahu Wa Ta'ala tetapkan dalam syariat-Nya yang agung dan tertuang dalam salah satu rukun dalam dien ini, yaitu zakat termasuk pula di dalamnya infak dan sedekah. Sebuah perintah dalam bentuk kewajiban untuk ditunaikan ummat Islam dari kalangan mampu untuk diberikan kepada saudaranya kaum muslimin yang tidak mampu sehingga tercipta kehidupan yang adil dan merata (Khatimah \& Nuradi, 2020a). Yang kemudian ditambahkan lagi oleh Fakhruddin (2011) 


\section{Jurnal Ilmiah Ekonomi Islam, 7(01), 2021, 24}

bahwa zakat dapat mengangkat harkat dan martabat kaum muslimin yang miskin dan mustadh'afin. Pengembangan kemampuan kelompok masyarakat miskin merupakan salah satu upaya dalam mengatasi kemiskinan dan sangat berkaitan dengan konsep pemberdayaan masyarakat (Khatimah \& Nuradi, 2020b). Pemberdayaan masyarakat merupakan sebuah proses mendukung masyarakat yang memiliki keterbatasan sumber daya, kaum wanita, dan kelompok masyarakat termajinalkan lainnya agar mampu meningkatkan kesejahteraan hidupnya sendiri yang dijalankan secara mandiri, proses ini berangkat dari upaya menjadikan masyarakat yang mandiri agar mampu meningkatkan taraf hidupnya sendiri dan keluarganya dengan mengoptimalkan sumber daya yang ada pada dirinya baik ditunjang faktor sumber daya alam maupun sumber daya manusia di lingkungan ia berada (Effendi \& Wirawan, 2013).

Hafidhuddin (2002) dalam Maghfiroh (2013) menguraikan bahwa ekonomi syariah memiliki tiga pilar utama yang saling berkaitan satu sama lain di antaranya sektor riil atau perdagangan yang membutuhkan perhatian ekstra dari berbagai pihak, sektor lembaga keuangan syariah, dan sektor zakat, infak dan sedekah yang memerlukan pendayagunaan yang optimal. ZIS memiliki peranan sebagai sumber dana sosial ekonomi ummat yang pendayagunaanya dapat dikelola oleh badan atau lembaga amil zakat secara produktif sehingga tidak terbatas pemanfaatan secara konvensional semata melainkan lebih dari itu, dengan memberikan zakat produktif sebagai bantuan modal usaha dapat dijadikan program pengentasan kemiskinan dan pengangguran. Hal ini sejalan dengan peran negara dalam mendukung pengelolaan zakat secara profesional melalui UU RI No. 23 Tahun 2011 (Prahest \& Putri, 2018), yang kemudian dilanjutkan dalam ruang lingkup kabupaten dengan didirikannya BAZNAS Kabupaten Sukabumi sebagai badan resmi pengelola zakat yang telah disahkan negara dengan berbagai program pemberdayaan berupa: Sukabumi Taqwa, Sukabumi Cerdas, Sukabumi Makmur, Sukabumi Peduli, dan Sukabumi Sejahtera (Sukabumi, 2014). Sutarji (2017) menjelaskan bahwa BAZNAS Kab. Sukabumi memiliki program pemberdayaan mustahiq zakat meliputi program BUMI (Bangkit Usaha Mikro) dan non BUMI. BUMI merupakan bantuan yang dialokasikan untuk pendayagunaan zakat produktif dalam bentuk bantuan modal usaha mikro dan bagian dari program Sukabumi Sejahtera yang bertujuan untuk melawan praktek riba yang telah lama menjerat kondisi perekonomian masyarakat miskin dengan slogannya Bina Rupah Bina Ruhiyah, dengan melakukan pembinaan Ruhani (Ngaji) dan Rupiah (Ngejo) yaitu mengembalikan ruhiyah masyarakat yang dibina di dalamnya, sedangkan non BUMI merupakan alokasi dari zakat konsumtif untuk para mustahiq fakir miskin yang yang sudah tua (udzur) dan cacat yang tidak memungkinkan lagi bagi mereka untuk melakukan suatu usaha.

Penelitian mengenai program pemberdayaan di sebuah badan atau lembaga zakat telah dilakukan sejumlah peneliti sebelumnya yang relevan dengan dengan studi ini, yaitu Pertama, Nugrahani \& Mulyawisdawati (2019) tentang Peran Zakat Produktif dalam Pemberdayaan Mustahiq (Studi Kasus Lembaga Amil Zakat Dompet Dhuafa Republika Yogyakarta 2017), Jurnal Ekonomi Syariah Indonesia, Volume IX, No. 1, Juni, 2019 dengan hasil penelitian menunjukkan bahwa peran zakat produktif dalam pemberdayaan ekonomi mustahiq pada Lembaga Amil Zakat Dompet Dhuafa Republika Yogyakarta melalui pengadaan program pemberdayaan yang sumber dananya berasal dari zakat produktif seperti program Kampung Ternak dan Institusi Mentas Unggul yang dilakukan dengan memberikan sosialisasi, penyuluhan, motivasi dan pembinaan yang berkelanjutan bagi mitra yang diberdayakan. Kedua, Dewi (2017) berkaitan Strategi Pendayagunaan Zakat Produktif untuk Pemberdayaan Kesejahteraan Mustahiq ( Studi Kasus pada LAZIS NU Kabupaten Banyumas), JPA, Volume 18, No. 12, Juli-Desember, 2017, yang hasil penelitiannya mengungkapkan bahwa pendayagunaan zakat produktif melalui pemberdayaan mustahiq mengikuti aturan LAZIS NU Pusat pada tahun 2017 berupa program pendidikan, ekonomi, kesehatan dan bencana yang dinilai sudah berlangsung secara efektif yang dapat diukur dengan melibatkan unsur ketepatan program, sosialisasi program, tujuan program dan pemantauan program. Dari penjabaran penelitian sebelumnya maka dapat dilihat bahwa kebaruan yang ada dalam penelitian ini yang berbeda dengan studi yang sudah ada sebelumnya yaitu, objek atau tempat penelitian yang berlokasi di BAZNAS Kabupaten Sukabumi dan fokus penelitian terhadap program unggulan Bangkit Usaha Mikro berbasis Masjid Desa Peradaban Zakat (BUMI DPZ) yang dijalankan mengikuti faktor sosial budaya masyarakat setempat, dengan melakukan pemberdayaan secara spiritual dan 
material sekaligus sesuai dengan mottonya ngaji (ruhani) atau pemberdayaan secara spiritual dan ngejo (rupiah) atau pemberdayaan secara material, sebuah program pemberdayaan yang belum dijalankan oleh lembaga atau badan amil zakat lainnya, oleh karena itu tujuan dari penelitian ini adalah untuk mengetahui tingkat keberhasilan program pemberdayaan mustahiq melalui program BUMI DPZ di BAZNAS Kabupaten Sukabumi.

\section{METODE PENELITIAN}

Penelitian yang akan dilakukan adalah penelitian survei, penulis akan melakukan wawancara dengan menggunakan kuesioner. Metode analisis yang digunakan pada penelitian ini adalah metode analisis deskriptif dengan menggunakan pendekatan kualitatif, yaitu dengan mengumpulkan fakta di lapangan hasil wawancara berupa kuesioner dengan responden. Penulis mengambil sampel responden untuk diwawancarai dan diberikan kuesioner sebanyak 57 orang di antaranya 20 orang dari Kecamatan Jampangtengah, 10 orang dari Kecamatan Purabaya, 6 orang dari Kecamatana Cikakak, dan 21 orang dari Kecamatan Nagrak.

\section{HASIL DAN PEMBAHASAN}

\subsection{Hasil penelitian}

Sebelum membahas lebih jauh mengenai analisis sejauh mana keberhasilan program pemberdayaan mustahiq yang telah dijalankan oleh BAZNAS Kabupaten Sukabumi dengan program unggulannya yang disebut dengan Bangkit Usaha Mikro berbasis masjid Desa Peradaban Zakat atau yang biasa disingkat dengan BUMI DPZ, terlebih dahulu kami paparkan dana yang telah dialokasikan untuk pengembangan program tersebut beserta data daerah yang telah mengikuti program ini yang dapat dilihat pada tabel berikut.

Tabel 1. Data Realisasi Dana Program BUMI-

DPZ BAZNAS Kabupaten Sukabumi Tahun

\begin{tabular}{ccc}
\multicolumn{2}{c}{$\mathbf{2 0 1 4 - 2 0 1 7}$} \\
\hline No & Tahun & Dana Program BUMI-DPZ \\
\hline 1 & 2014 & 287.285 .000 \\
2 & 2015 & 878.286 .000 \\
3 & 2016 & 383.000 .000 \\
4 & 2017 & 425.000 .000 \\
\hline
\end{tabular}

Tabel 2. Rekapitulasi Peserta BUMI-DPZ Tingkat Kecamatan Tahun 2011-2016

\begin{tabular}{|c|c|c|c|}
\hline No & Th & Kecamatan & $\begin{array}{l}\text { Jumlah } \\
\text { Peserta }\end{array}$ \\
\hline 1 & 2011 & $\begin{array}{l}\text { Kec. Jampangtengah Masjid } \\
\text { al-Mukaromah }\end{array}$ & 30 \\
\hline 2 & 2011 & $\begin{array}{l}\text { Kec. Purabaya Masjid al- } \\
\text { Ittihad }\end{array}$ & 20 \\
\hline 3 & 2011 & $\begin{array}{l}\text { Kec. Cikakak Masjid Nurul } \\
\text { Islam }\end{array}$ & 30 \\
\hline 4 & 2011 & $\begin{array}{l}\text { Kec. Jampangkulon Masjid } \\
\text { Nurul Hidayah }\end{array}$ & 20 \\
\hline 5 & 2013 & Kec. Cisaat - Sofwatul Ikhwan & 25 \\
\hline 6 & 2013 & Kec. Ciracap Masjid al-Ikhlas & 25 \\
\hline 7 & 2013 & $\begin{array}{l}\text { Kec. Cidolog Masjid Nurul } \\
\text { Iman }\end{array}$ & 25 \\
\hline 8 & 2013 & $\begin{array}{l}\text { Kec. Cikidang Masjid al- } \\
\text { Barokah }\end{array}$ & 25 \\
\hline 9 & 2013 & $\begin{array}{l}\text { Kec. Sukaraja Masjid al- } \\
\text { Muttaqien }\end{array}$ & 25 \\
\hline 10 & 2013 & Kec. Kalapanunggal Masjid & 25 \\
\hline 11 & 2013 & $\begin{array}{l}\text { Kec. Nyalindung Masjid } \\
\text { Kalapanunggal }\end{array}$ & 25 \\
\hline 12 & 2014 & $\begin{array}{l}\text { Kec. Parakansalak Masjid at- } \\
\text { Taqwa }\end{array}$ & 25 \\
\hline 13 & 2014 & $\begin{array}{l}\text { Kec. Pabuaran Masjid } \\
\text { Darussalam }\end{array}$ & 25 \\
\hline 14 & 2014 & $\begin{array}{l}\text { Kec. Cireunghas - WCC } \\
\text { Sukabumi }\end{array}$ & 25 \\
\hline 15 & 2014 & $\begin{array}{l}\text { Kec. Tegalbuleud Masjid al- } \\
\text { Istiqomah }\end{array}$ & 25 \\
\hline 16 & 2014 & $\begin{array}{l}\text { Kec. Kadudampit Masjid al- } \\
\text { Fadlah }\end{array}$ & 23 \\
\hline 17 & 2014 & $\begin{array}{l}\text { Kec. Sagaranten Masjid Nurul } \\
\text { Yakin }\end{array}$ & 25 \\
\hline 18 & 2014 & Kec. Caringin Masjid al-Bayan & 25 \\
\hline 19 & 2015 & $\begin{array}{l}\text { Kec. Curugkembar Masjid at- } \\
\text { Taufiq }\end{array}$ & 25 \\
\hline 20 & 2015 & $\begin{array}{l}\text { Kec. Cisolok Masjid Darul } \\
\text { Amal }\end{array}$ & 25 \\
\hline 21 & 2015 & $\begin{array}{l}\text { Kec. Kabandungan Masjid } \\
\text { Miftahussa'adah }\end{array}$ & 25 \\
\hline 22 & 2015 & $\begin{array}{l}\text { Kec. Cidolog Masjid al- } \\
\text { Istiqomah }\end{array}$ & 25 \\
\hline 23 & 2015 & $\begin{array}{l}\text { Kec. Parungkuda Masjid al- } \\
\text { Hikmah }\end{array}$ & 25 \\
\hline 24 & 2015 & Kec. Cicurug Masjid al-Ikhlas & 25 \\
\hline 25 & 2015 & Kec. Sukalarang & 25 \\
\hline 26 & 2015 & $\begin{array}{l}\text { Kec. Bantargadung Masjid } \\
\text { Babusalam }\end{array}$ & 23 \\
\hline
\end{tabular}




\begin{tabular}{|c|c|c|c|}
\hline No & Th & Kecamatan & $\begin{array}{l}\text { Jumlah } \\
\text { Peserta }\end{array}$ \\
\hline 27 & 2015 & $\begin{array}{l}\text { Kec. Sukabumi Masjid al- } \\
\text { Muttaqin }\end{array}$ & 25 \\
\hline 28 & 2015 & $\begin{array}{l}\text { Kec. Cibitung Masjid } \\
\text { Baiturrahman }\end{array}$ & 25 \\
\hline 29 & 2015 & $\begin{array}{l}\text { Kec. Cicantayan Masjid al- } \\
\text { Marzukiyah }\end{array}$ & 25 \\
\hline 30 & 2015 & $\begin{array}{l}\text { Kec. Palabuhanratu Masjid } \\
\text { Nurul Huda }\end{array}$ & 25 \\
\hline 31 & 2015 & $\begin{array}{l}\text { Kec. Cilengkong Masjid al- } \\
\text { Falah }\end{array}$ & 25 \\
\hline 32 & 2015 & $\begin{array}{l}\text { Kec. Kebonpedes Masjid al- } \\
\text { Fatah }\end{array}$ & 25 \\
\hline 33 & 2015 & Kec. Cidadap Masjid al-Huda & 25 \\
\hline 34 & 2015 & Kec. Ciemas Masjid as-Safa & 25 \\
\hline 35 & 2015 & $\begin{array}{l}\text { Kec. Simpenan Masjid Nurul } \\
\text { Hidayah }\end{array}$ & 25 \\
\hline 36 & 2015 & $\begin{array}{l}\text { Kec. Bojong Genteng Masjid } \\
\text { Darussalam }\end{array}$ & 25 \\
\hline 37 & 2015 & $\begin{array}{l}\text { Kec. Ciambar Masjid } \\
\text { Darussalam }\end{array}$ & 25 \\
\hline 38 & 2015 & $\begin{array}{l}\text { Kec. Kalibunder Masjid al- } \\
\text { Istiqomah }\end{array}$ & 25 \\
\hline 39 & 2015 & $\begin{array}{l}\text { Kec. Cimanggu Masjid } \\
\text { Miftahul Falah }\end{array}$ & 25 \\
\hline 40 & 2015 & $\begin{array}{l}\text { Kec. Cicurug Masjid al- } \\
\text { Hidayah }\end{array}$ & 25 \\
\hline 41 & 2015 & $\begin{array}{l}\text { Kec. Warungkiara Masjid Jami } \\
\text { Nurul Huda }\end{array}$ & 25 \\
\hline 42 & 2016 & Kec. Cisaat Masjid an-Nashir & 25 \\
\hline 43 & 2016 & $\begin{array}{l}\text { Kec. Cibadak Masjid al- } \\
\text { Mubarok }\end{array}$ & 25 \\
\hline 44 & 2016 & $\begin{array}{l}\text { Kec. Kalapanunggal Masjid al- } \\
\text { Muhajirin }\end{array}$ & 25 \\
\hline 45 & 2016 & $\begin{array}{l}\text { Kec. Purabaya Masjid } \\
\text { Baiturrohim }\end{array}$ & 25 \\
\hline
\end{tabular}

Berdasarkan data yang tercantum pada tabel di atas maka dapat dilihat bahwasannya jumlah kecamatan yang mengikuti program BUMI DPZ meningkat setiap tahunnya terutama pada tahun 2015 terjadi peningkatan yang cukup signifikan yaitu, sebanyak 23 kecamatan dengan beberapa tambahan kecamatan baru yang memperoleh bantuan program ini. Hal ini selaras dengan jumlah realisasi dana program tersebut di tahun 2015 yang cukup besar sebanyak Rp 878.286.000 jika dibandingkan dengan tahun sebelum dan setelahnya.

Dari sejumlah data populasi peserta program BUMI DPZ di atas penulis mengambil sampel responden untuk diwawancarai dan diberikan kuesioner sebanyak 57 orang di antaranya 20 orang dari Kecamatan Jampangtengah, 10 orang dari Kecamatan Purabaya, 6 orang dari Kecamatana Cikakak, dan 21 orang dari Kecamatan Nagrak yang merupakan responden yang telah berhasil dalam pembinaan atas rekomendasi dari pendamping dan koordinatornya setelah melakukan wawancara dengan mereka.

\section{Karakteristik Demografi Responden}

Dari jumlah responden yang diambil dalam penelitian ini sebanyak 57 orang, berikut penulis mendeskripsikan beberapa karakteristik demografi responden beserta diagramnya yang mencakup jenis kelamin, usia, pendidikan formal, dasar pendidikan, pendidikan non formal, pekerjaan, usaha sebelumnya, pendapatan, dan jumlah tanggungan. Hal ini sebagaimana yang dikemukakan oleh Hamzah (2015) dan Asdiansyuri (2016) bahwa karakteristik tersebut berpengaruh terhadap keberhasilan pemberdayaan mustahiq.

Tabel 3. Karakteristik Demografi Responden

\begin{tabular}{|c|c|c|c|}
\hline & Jenis Kelamin & & Pendidikan Formal \\
\hline Pria & $14,04 \%$ & Tidak Ada & $3,51 \%$ \\
\hline \multirow[t]{2}{*}{ Wanita } & $85,96 \%$ & SD-SMP & $64,91 \%$ \\
\hline & Dasar Pendidikan & SMA-S1 & $31,58 \%$ \\
\hline Tidak Ada & $3,51 \%$ & & Pendidikan Non Formal \\
\hline Sekolah Umum & $68,42 \%$ & Menjahit & $12,28 \%$ \\
\hline Madrasah/ Pesantren & $28,07 \%$ & Tata Boga & $14,04 \%$ \\
\hline \multicolumn{2}{|r|}{ Usia } & Montir & $0,00 \%$ \\
\hline SD 20 Tahun & $0,00 \%$ & Komputer & $0,00 \%$ \\
\hline 21-30 Tahun & $3,50 \%$ & Lainnya & $73,68 \%$ \\
\hline 31-40 Tahun & $26,32 \%$ & & Pekerjaan \\
\hline 41-50 Tahun & $54,39 \%$ & Petani & $3,51 \%$ \\
\hline$>50$ Tahun & $15,79 \%$ & Nelayan & $0,00 \%$ \\
\hline
\end{tabular}




\begin{tabular}{|c|c|c|c|c|}
\hline & Usaha Sebelumnya & Pedagang & & $45,61 \%$ \\
\hline Tidak Ada & $21,05 \%$ & Buruh & & $14,04 \%$ \\
\hline Beternak & $1,75 \%$ & Lainnya & & $36,84 \%$ \\
\hline Bertani & $3,51 \%$ & \multicolumn{3}{|c|}{ Tanggungan } \\
\hline Warung & $42,11 \%$ & \multirow{4}{*}{$\begin{array}{l}4 \text { orang } \\
6 \text { orang } \\
8 \text { orang } \\
>8 \text { orang }\end{array}$} & \\
\hline \multirow[t]{2}{*}{ Lainnya } & $31,58 \%$ & & \multicolumn{2}{|l|}{$17,54 \%$} \\
\hline & Pendapatan & & $8,77 \%$ & \\
\hline Tidak Ada & $3,51 \%$ & & $0,00 \%$ & \\
\hline$<\operatorname{Rp} 500.000$ & $59,65 \%$ & Lainnya & $31,58 \%$ & \\
\hline Rp 500.000-Rp & & & & \\
\hline 1.000 .000 & $36,84 \%$ & & & \\
\hline
\end{tabular}

Diagram 1. Jenis Kelamin Responden Peserta Program BUMI BAZNAS Kabupaten Sukabumi

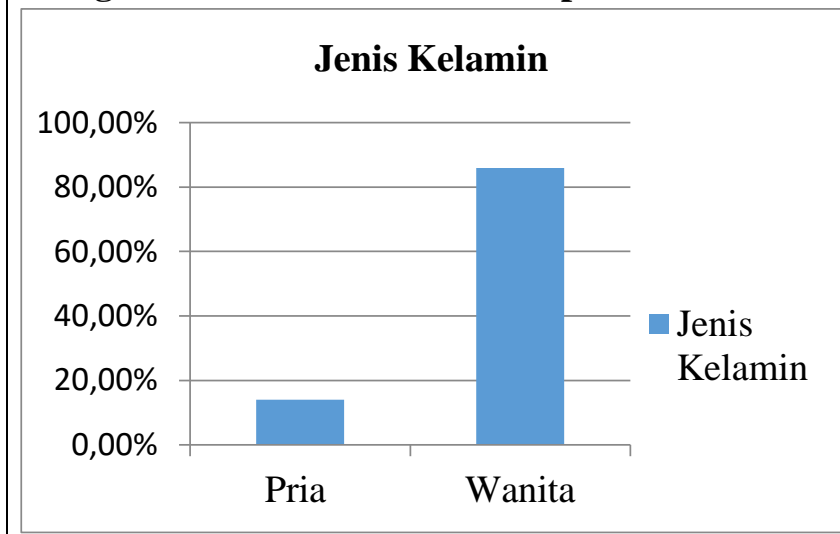

Berdasarkan diagram di atas terlihat bahwa responden paling banyak dari jenis kelamin wanita yaitu sebanyak $85,96 \%$ atau 49 orang responden dari total 57 orang responden, sedangkan 14,04\% responden lainnya atau 8 orang berjenis kelamin pria, yang deskripsinya dapat dilihat pada diagram di bawah. Hal ini menunjukkan bahwa peserta program BUMI didominasi dari kalangan wanita, yang sesuai dengan wawancara penulis dengan pendamping koordinator BUMI bahwa program ini lebih banyak diikuti dari kalangan ibu-ibu.

Pada diagram selanjutnya, dari segi usia kelompok usia 41-50 tahun yang paling banyak yang menjadi peserta program BUMI BAZNAS Kabupaten Sukabumi yaitu, sebanyak $54,39 \%$ atau 31 orang responden, di posisi kedua pada rentang usia 31-40 tahun yaitu, sebanyak $26,32 \%$ atau 15 orang responden, posisi ketiga pada rentang usia $>50$ tahun sebanyak $15,79 \%$ atau 9 orang responden, dan di posisi terakhir pada rentang usia 21-30 tahun sebesar $3,50 \%$ atau hanya sebanyak 2 orang responden, sedangkan rentang usia sampai dengan 20 tahun tidak ada yang menjadi responden dalam penelitian ini atau belum ada yang menjadi peserta program BUMI BAZNAS Kabupaten Sukabumi. Hal ini menunjukkan bahwa peserta program BUMI didominasi rentang usia 41-50 tahun yang dapat dilihat deskripsinya pada diagram berikut.

\section{Diagram 2. Usia Responden Peserta Program BUMI BAZNAS Kabupaten Sukabumi}

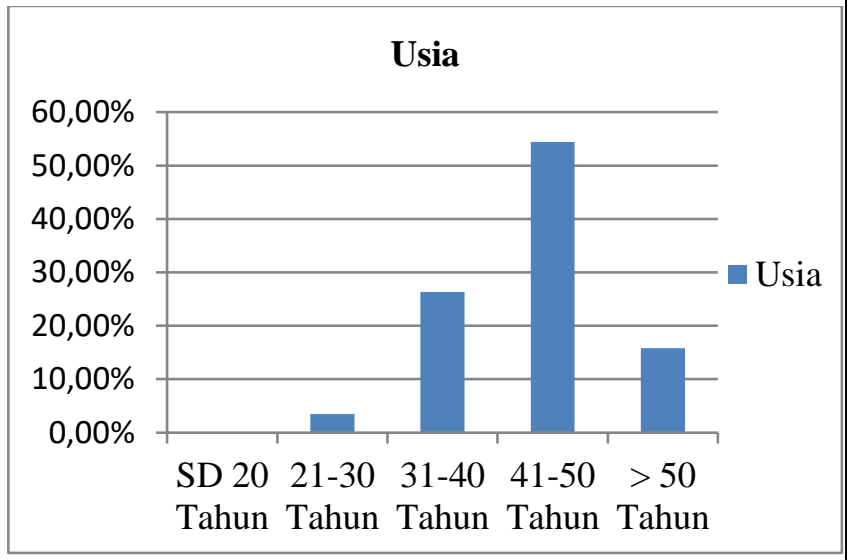

Pada diagram pendidikan formal di atas terlihat bahwa tingkat pendidikan terakhir setingkat SD-SMP merupakan jumlah responden terbanyak yaitu, sebesar $64,91 \%$ atau 37 orang respoden. Di posisi kedua diduduki oleh pendidikan terakhir setingkat SMA-S1 yaitu, sebesar $31,58 \%$ atau 18 orang, dan di posisi terakhir ditempati responden yang tidak menempuh pendidikan sebesar 3,51\% atau 2 orang responden. Hal ini menunjukkan bahwa peserta program BUMI BAZNAS kabupaten Sukabumi didominasi tingkat pendidikan setara SD-SMP, yang deskripsinya dapat dilihat pada diagram di bawah ini.

Diagram 3. Tingkat Pendidikan Formal

\section{Responden Peserta Program BUMI BAZNAS Kabupaten Sukabumi}

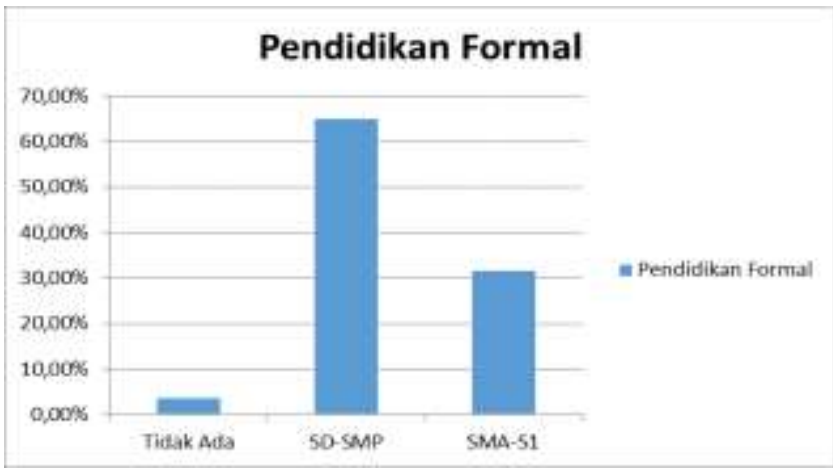


Pada diagram tentang dasar pendidikan terlihat bahwa responden terbanyak dari sekolah umum sebesar $68,42 \%$ atau 39 orang, sedangkan respoden dengan dasar pendidikan pesantren berada di posisi kedua hanya sebesar $28,07 \%$ atau 16 orang, dan di posisi terakhir sebesar 3,51\% atau 2 orang saja yang tidak memiliki dasar pendidikan di antara keduanya karena tidak menempuh pendidikan seperti pada tabel pendidikan formal. Hal ini menunjukkan bahwa peserta program BUMI didominasi masyarakat yang dasar pendidikan sekolah umum, hasil ini berbeda saat wawancara dengan koordinatornya bahwa peserta pada umumnya lebih banyak dari sekolah madrasah atau pesantren. Atau bisa jadi yang menjadi responden bukanlah yang disebutkan oleh pendamping mengingat peneliti hanya menemukan 57 respoden dari +/- 1000 peserta program BUMI. Deskripsi dari dasar pendidkan responden dapat dilihat pada digaram di bawah ini.

\section{Diagram 4. Tingkat Pendidikan Non Formal \\ Responden Peserta Program BUMI BAZNAS Kabupaten Sukabumi}

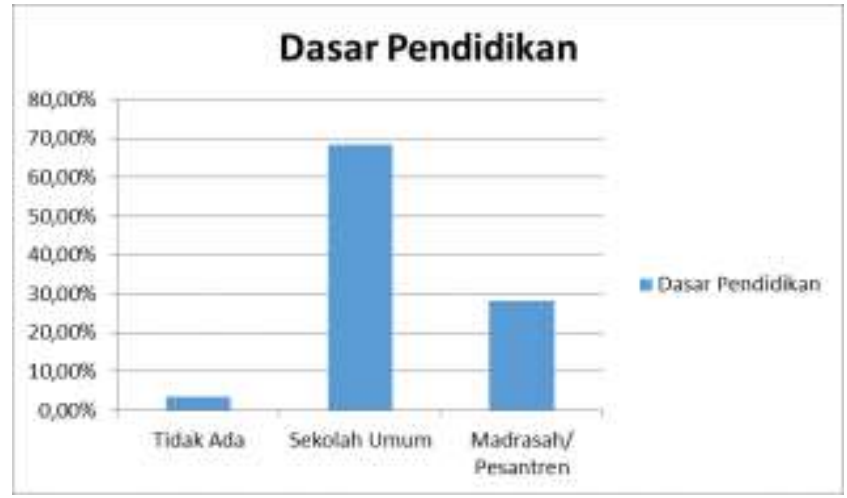

Selain tingkat pendidikan formal berikut pula deskripsi tingkat pendidikan non formal dengan responden terbanyak pada posisi lainnya yaitu, sebesar $73,68 \%$ atau 42 orang atau dalam artian peserta pogram BUMI didominasi masyarakat yang tidak mengikuti pelatihan apapun sebelum memperoleh pendampingan dari pihak BAZNAS Kabupaten Sukabumi. Kemudian disusul responden yang pernah mengikuti kursus tata boga sebesar $14,04 \%$ atau 8 orang, disusul responden yang pernah mengikuti kursus menjahit sebesar $12,28 \%$ atau 7 orang. Sedangkan, kursus montir dan komputer tidak pernah diikuti responden, yang deskripsinya dapat dilihat lebih jelas pada diagram berikut.

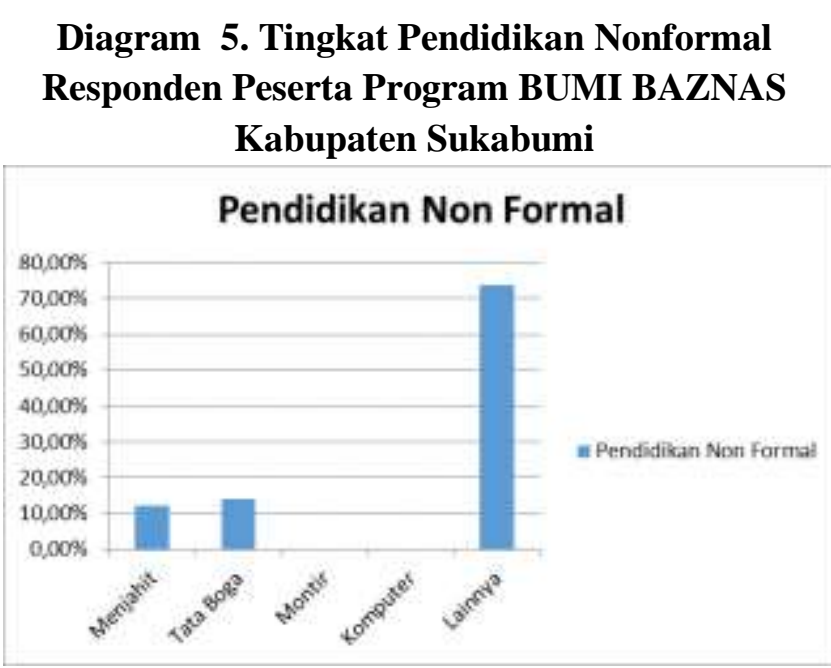

Berdasarkan data yang tercantum pada diagram di atas terlihat bahwa jumlah pekerjaan responden terbanyak pada pedagang yaitu, sebesar $45,61 \%$ atau 26 orang, diikuti di posisi kedua pekerjaan lainnya sebesar $36,84 \%$ atau 21 orang di antaranya yaitu, guru, IRT, beternak, dan penjahit. Kemudian, disusul pada posisi ketiga responden dengan jenis pekerjaan sebagai buruh yaitu, sebesar $14,04 \%$ atau 8 orang selanjutnya di posisi keempat responden dengan pekerjaan sebagai petani sebesar 3,50\% atau 2 orang. Di posisi paling terakhir pekerjaan sebagai nelayan tidak digeluti oleh responden mengingat wilayah penelitian berada di atas dataran tinggi sehingga jauh dari perairan (laut). Berikut diagram dari deskripsi jenis pekerjaan responden.

\section{Diagram 6. Pekerjaan Responden Peserta Program BUMI BAZNAS Kabupaten Sukabumi}

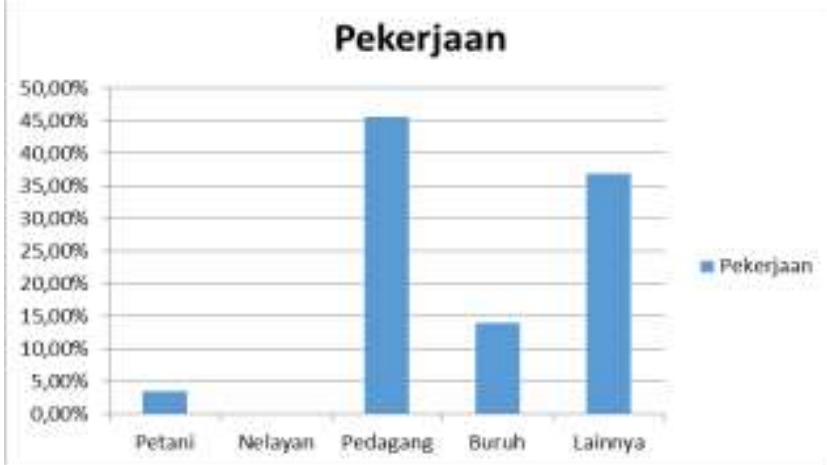

Selain jenis pekerjaan yang telah digeluti sekarang, berikut deskripsi usaha yang digeluti responden sebelum mengikuti program pemberdayaan BUMI BAZNAS Kabupaten Sukabumi. Di posisi tertinggi respoden dengan menjalankan usaha warung sebesar $42,11 \%$ atau 24 orang, selanjutnya di posisi kedua respoden dengan usaha lainnya yang tidak termasuk ke dalam chart sebesar $31,58 \%$ atau sebanyak 18 orang ini didominasi respoden yang berprofesi sebagai pedagang keliling dan belum 
memiliki warung. Berikutnya di posisi ketiga responden yang sebelumnya tidak memiliki usaha sebelum mengikuti program pemberdayaan sebesar $21,05 \%$ atau 12 orang yang umumnya IRT. Posisi selanjutnya ditempati responden dengan usaha sebelumnya bertani sebesar $3,51 \%$ atau 2 orang dan disusul bertani sebesar $1,75 \%$ atau 1 orang responden saja. Deskripsi tersebut dapat dilihat pada diagram di bawah ini.

\section{Diagram 7. Usaha Sebelumnya Responden} Peserta Program BUMI BAZNAS Kabupaten Sukabumi

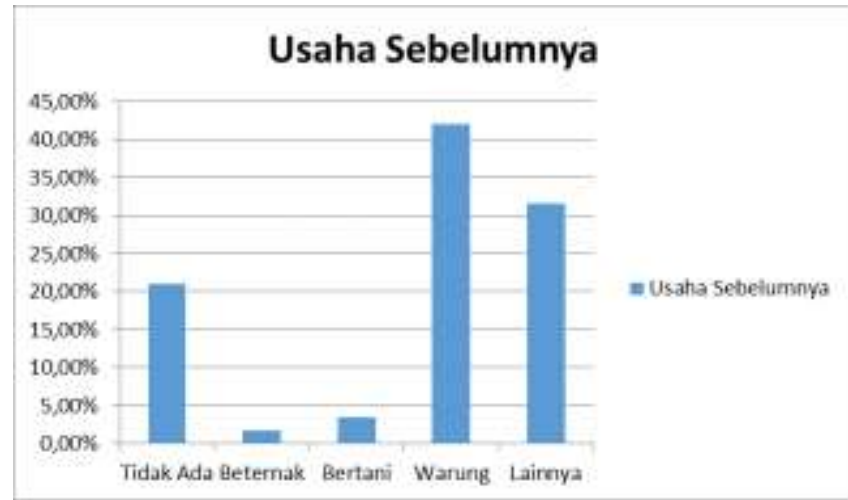

Selanjutnya pada diagram tanggungan responden dengan jumlah tanggungan sebanyak 4 orang mendominasi dengan perolehan persentase tertinggi sebesar $42,11 \%$ atau 24 orang, kemudian responden dengan tanggungan dengan pilihan lainnya sebesar 31,58 atau 18 orang umumnya tidak lagi memiliki anak yang ditanggung atau tinggal seorang diri atau jumlah anggota keluarganya tidak ada di pilihan kuesioner. Posisi ketiga ditempati responden dengan jumlah tanggungan sebanyak 6 orang yaitu, sebesar $17,54 \%$ atau 10 orang, diikuti responden dengan tanggungan sebanyak 8 orang sebesar $8,77 \%$ atau 5 orang, dan responden dengan tanggungan $>8$ orang tidak ada dalam penelitian ini. Deskripsi tersebut dapat dilihat pada diagram di bawah ini.

Diagram 8. Jumlah Tanggungan Responden Peserta Program BUMI BAZNAS Kabupaten Sukabumi

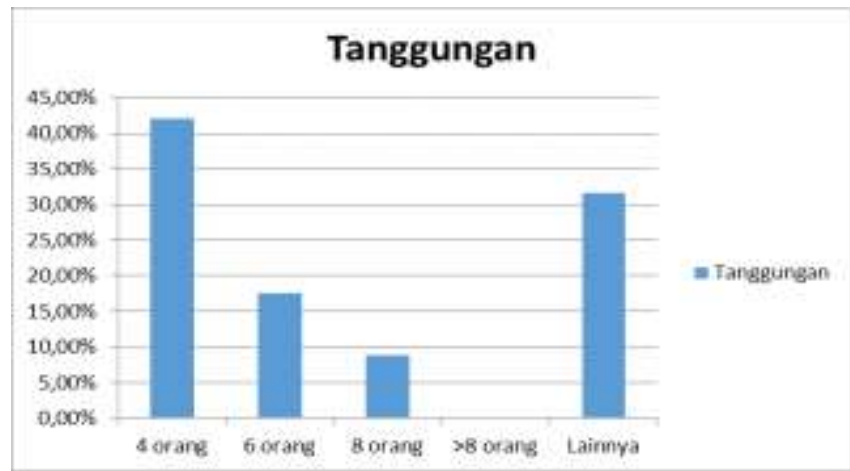

Pada diagram pendapatan, responden dengan pendapatan $<\mathrm{Rp} 500,000$ menempati persentase tertinggi sebesar $59,65 \%$ atau 34 orang, disusul responden dengan penghasilan $\mathrm{Rp}$ 500,000-Rp $1,000,000$ sebesar $36,84 \%$ atau 21 orang, dan yang paling terakhir responden yang tidak memiliki pendapatan sebesar 3,51\% atau 2 orang karena tidak memiliki pekerjaan seperti yang ada pada tabel pekerjaan di atas dan deskripsi dari jumlah pendapatan responden penerima bantuan program BUMI BAZNAS Kabupaten Sukabumi dapat dilihat pada diagram di bawah ini.

Diagram 9. Jumlah Pendapatan Responden Peserta Program BUMI BAZNAS Kabupaten

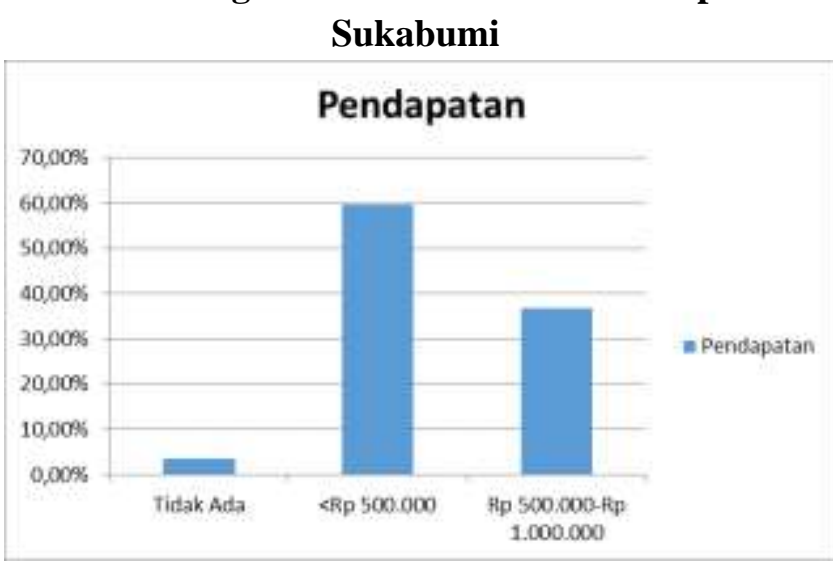

\subsection{Pembahasan}

Responden dari kecamatan Jampangtengah lebih banyak karena di wilayah tersebut lah pertama kali dilaksanakan program pemberdayaan sekaligus menjadi desa percontohan Desa Peradaban Zakat yang menjadi icon pelaksanaan syariat Islam di Kabupaten Sukabumi yang dikenal sebagai kota santri. Bahkan Desa Panumbangan Kecamatan Jampangtengah selalu berada di posisi pertama pengumpulan dan pengelolaan zakat fitrah se-Kabupaten Sukabumi, yang merupakan pusat dari desa percontohan peradaban zakat yang ada di Kabupaten Sukabumi, selain itu Masjid al-Muhtadin yang juga masih di wilayah kecamatan Jampangtengah tidak hanya mengelola dana zakat fitrah tetapi juga zakat maal sesuatu yang belum dijalankan di DPZ masjid lainnya, mengingat fokus pengelolaan zakat masih berpusat pada zakat fitrah semata, yang tentu juga dikondisikan dengan tingkat ekonomi masyarakat. Kemudian tingkat keberhasilan program ini lebih banyak terdapat di daerah tersebut karena seperti dipaparkan di atas daerah ini pertama kali dirintis program ini sehingga populasi yang berhasil pun lebih tinggi bila dibandingkan dengan wilayah lain atau dengan kata 
lain programnya telah berlangsung lama. Mereka sudah ikut program tersebut sejak tahun 2011 sebagaimana data pada tabel di atas di antara 25 orang peserta awal yang tetap survive (bertahan) bahkan berhasil di dalamnya sebanyak 2 orang dengan bantuan awal modal usaha Rp 1,000,000 per partisipan dan sekarang mereka telah memiliki berbagai usaha di antaranya, Bu Ratna dengan toko kelontongannya, usaha kredit pakaian, perlengkapan rumah tangga, dan alat elektronik yang dijalankan oleh Bu Atika bahkan mampu menjadi kafil (wali) 3 orang anak yatim di sebuah madrasah ibtidaiyah depan rumahnya.

Di BAZNAS Kabupaten Sukabumi sendiri program pemberdayaan mustahiq zakat meliputi program BUMI dan non BUMI. BUMI merupakan bantuan yang dialokasikan untuk pendayagunaan zakat produktif dalam bentuk bantuan modal usaha mikro, yang merupakan pengejawantahan UU No. 38 Tahun 1999 yang kemudian direvisi menjadi UU No. 23 Tahun 2011 tentang pengelolaan zakat yang dapat digunakan untuk usaha produktif (Anwar, 2016), sedangkan non BUMI merupakan alokasi dari zakat konsumtif untuk para mustahiq fakir miskin yang yang sudah tua (udzur) dan cacat yang tidak memungkinkan lagi bagi mereka untuk melakukan suatu usaha, sebagaimana telah dikemukakan Didin Hafidhuddin (2002) dalam (Komariah \& Damayanti, 2015) bahwa zakat dapat disalurkan kepada mustahiq dalam bentuk produktif dan konsumtif, dimana penulis lebih fokus terhadap program BUMI karena sejalan dengan fokus penelitian untuk melihat sejauh mana keberhasilan dari program tersebut melihat adanya proses pendampingan dan pemantauan seberapa efektif jalannya program tersebut. Suatu hal yang tidak terdapat pada program non BUMI, yang mana keduanya merupakan pemberian bantuan usaha kepada masyarakat miskin namun, non BUMI tidak terukur dan tidak terdata sehingga sulit untuk mengukur tingkat keberhasilan program tersebut. Selain itu, dana yang dialokasikan pun lebih sedikit karena kembali lagi ke permasalahan awal bahwa tidak ada proses pendampingan termasuk di dalamnya pemantauan, motivasi dan evaluasi sebagaimana yang ada pada program BUMI. Berdasarkan hasil wawancara penulis dengan koordinator BUMI Kec. Nagrak (Herlan, 2017) yang menyatakan bahwa BUMI merupakan bagian dari program Sukabumi Sejahtera yang bertujuan untuk melawan praktek riba yang telah lama menjerat kondisi perekonomian masyarakat miskin dengan slogannya Bina Rupah Bina Ruhiyah, dengan melakukan pembinaan Ruhani (Ngaji) dan Rupiah (Ngejo) yaitu mengembalikan ruhiyah masyarakat yang dibina di dalamnya, sehingga mereka tidak hanya terberdayakan secara materi, namun yang lebih utama dari segi spiritual. Program ini telah digulirkan sejak tahun 2013 dengan memberikan bantuan pinjaman usaha sebesar Rp 1.000.000 yang angsurannya sebesar Rp 25.000 setiap pekan dalam sebulan atau sebanyak empat kali yang harus dilunasi selama 10 bulan dengan infak sebesar Rp 2.000 setiap pertemuan pekanan. Pada awal pembinaan dan pemberian bantuan usaha para anggota diwajibkan hadir dalam pertemuan selama 40 hari. Program ini sangat membantu masyarakat ekonomi menengah dan menengah ke bawah, yang apabila berjalan sebagaimana mestinya dan mereka aktif mengembalikan pinjaman maka akan dibentuk koperasi syariah untuk para mustahiq seperti yang telah dipaparkan di awal profil BAZNAS Kabupaten Sukabumi. Namun, tingkat keberhasilan program ini masih rendah karena disebabkan berbagai kendala berikut (Herlan, 2017):

a. Masih sulit merubah pola pikir masyarakat dari konsumtif ke produktif, meskipun sudah mencoba memberikan bantuan usaha namun, bantuan usaha tersebut bukan digunakan untuk menjalankan untuk usaha produktif malah digunakan untuk konsumsi.

b. Faktor jenis kelamin juga berpengaruh terhadap keberhasilan anggota, di mana kaum perempuan teruatama ibu-ibu lebih aktif mengikuti kegiatan pembinaan dan pengajian dan disiplin mengembalikan pinjaman dibandingkan dengan binaan bapak-bapak yang cenderung sulit mengajak mereka hadir dalam kegiatan pekanan dan pengajian karena kendala kesibukan.

c. Pihak pendamping menghadapi persaingan berat dengan bank dan program lain yang memberikan pinjaman dengan sistem bunga, dikarenakan mereka lebih aktif mendatangi warga dengan memberikan pinjaman beserta bunganya yang tinggi dilengkapi dengan berbagai fasilitas yang lebih lengkap dan memadai. Kemudian pendamping harus siap pasang badan membela para binaan ketika mendapat tekanan dari pihak bank ketika tidak mampu melunasi hutang plus bunganya.

d. Program ini berhadapan dengan sistem negara yang telah melegalkan sistem riba dan kapitalis, 


\section{Jurnal Ilmiah Ekonomi Islam, 7(01), 2021, 31}

sehingga para pendamping yang berjuang di masyarakat bekerja lebih keras untuk menyadarkan masyarakat miskin untuk terlepas dari belenggu riba dan memperbaiki kualitas hidup para mustahiq dengan kembali menjalankan sistem ekonomi syariah melalui pemberian bantuan pinjaman usaha berupa qardhul hasan, maka selayaknya mereka pun disebut sebagai mujahid $f i$ sabililillah. Mereka tidak hanya berdakwah secara lisan mengenai larangan riba dan keutamaan sistem ekonomi Islam namun, langsung menunjukkkan praktek nyata keutamaan ekonomi syariah itu sendiri.

e. Mental para binaan telah terbiasa dimanjakan oleh sistem bunga sehingga ketika diperkenalkan sistem bagi hasil mereka masih sulit untuk menerima, terkadang masih banyak di antara mereka mengambil pinjaman dari BUMI dan bank sekaligus.

f. Kendala juga tidak hanya datang dari para mustahiq namun, juga dari pendamping, terhitung sejak awal berdiri pendamping hanya sebanyak 12 orang yang sekarang tinggal 10 orang sekabupaten belum lagi luas wilayah kabupaten Sukabumi yang mencapai 47 kecamatan yang harus mereka bina. Padahal pendamping berperan sebagai agen perubahan yang ikut andil dalam mengatasi masalah yang dihadapi para binaan, sehingga pendampingan dapat disebut sebuah interaksi dinamis antara pekerja sosial dan warga miskin untuk bersinergi menghadapi tantangan (Nugraha, 2009).

g. Tantangan yang paling berat pada pembinaan muallaf khususnya di daerah Cikidang, di mana muallaf tersebut bukanlah muallaf murni dari non muslim ke Islam namun, orang Islam yang murtad karena iming-iming bantuan harta karena kondisi mereka di bawah garis kemiskinan, kemudian oleh pihak BAZNAS dan tokoh agama di wilayah tersebut mengislamkan mereka kembali sambil diberikan pembinaan keagamaan dan bantuan usaha agar mereka tetap dalam keimanannya. Namun, karena telah terbiasa diberikan bantuan secara konsumtif oleh para misionaris, mereka belum bisa menjalankan program ini dengan tertib sebagaimana anngota lainnya di kecamatan lain.

Setelah pemaparan faktor penghambat yang dikemukakan di atas, berikutnya adalah faktor pendukung keberhasilan program BUMI (Herlan, 2017), yaitu: a. Para mustahiq yang dibina dan telah memiliki dasar aktif di majelis ta'lim sebelumnya maka akan lebih mudah merangkul mereka, kemudian mereka lebih tertib dan disiplin dalam mengembalikan pinjaman. Hal ini menunjukkan bahwa semakin bagus pemahaman agama seseorang maka akan semakin semakin bagus pula motivasinya berusaha mengubah keadaan hidupnya, selaras dengan penelitian (Mursyidah, 2019) bahwa tingkat religiusitas ini dinilai berpengaruh terhadap keberhasilan pemberdayaan mustahiq.

b. Adanya dukungan penuh dari Bupati Kabupaten Sukabumi sebagai pemilik otoritas dalam mengawal jalannya program ini serta peran aktif ulama, kyai, dan ustadz dalam menyadarkan ummat akan bahaya riba dan keuntungan kembali ke sistem Islam melalui sistem bagi hasil dan pinjaman dalam bentuk qardhul hasan. Terlihat bahwa ada sinergitas antara ulama dan umara' di Kabupaten Sukabumi dalam memberantas kemiskinan dan mencapai tujuan penerapan syariat Islam dan miniatur percontohan ekonomi syariah di Indonesia sekaligus menjadi pihak yang mengambil bagian dari peradaban yang pernah dibangun Rasulullah Shallallahu 'Alaihi Wasallam sebagaimana slogan awal program ini Membangun Peradaban Zakat, Peradaban Membangun Zakat. Terbukti dengan banyaknya Unit Pengumpulan Zakat (UPZ) di setiap tingkat Kecamatan, Desa, dan Masjid di Kabupaten Sukabumi serta ada kerja sama antara pihak BAZNAS dengan kecamatan dalam memberikan pendampingan bagi para mustahiq yang dibina.

Di antara indikator keberhasilan pembinaan anggota dapat dilihat dari segi kualitatif dan kuantitatif, di mana faktor kualitatif ditunjukkan dengan bagaimana agar bina ruhiyah dapat terealisasi berupa para binaan dapat berhijrah dari sistem ekonomi riba ke ekonomi syariah dan bagaimana agar ibadah individu dapat mereka jalankan meski tanpa pengarahan dan pengawasan lagi, bahkan dapat merubah mereka menjadi rajin ke masjid, aktivis masjid, dan jamaah tetap di dalamnya. Sedangkan, dari faktor kuantitatif bagaimana agar bina rupiahnya juga tercapai berupa anggota tersebut tertib membayar cicilan pinjaman, tertib menabung, dan tertib infaq. Maka dapat disimpulkan bahwa yang ingin dicapai dalam program ini agar keimanan dan usaha yang dijalankan para mustahiq dapat meningkat, dapat 
berjalan secara seimbang tanpa ada tumpang tindih satu sama lain terlebih lagi jika sisi materinya lebih dominan maka kekuatan keimanan sebagai tolok ukur keberhasilan dunia akhirat seorang pribadi muslim tidak akan tercapai sebagai mana mestinya.

\section{KESIMPULAN}

Berdasarkan uraian hasil penelitian di atas maka dapat disimpulkan bahwa tingkat keberhasilan program BUMI DPZ BAZNAS Kabupaten Sukabumi dari segi bina rupiah masih tergolong rendah karena berhadapan dengan berbagai hambatan di antaranya mental warga binaan (mustahiq) yang masih berorientasi konsumtif masih cukup sulit untuk merubah ke arah produktif dan sudah terbiasa dengan sistem riba ditambah lagi dengan terbatasnya jumlah pendamping yang sekaligus harus berhadapan dengan lembaga lain yang menawarkan program bantuan berupa pinjaman berbunga, padahal pendamping berperan besar dalam mengubah mindset masyarakat sekaligus agen perubahan untuk menciptakan kondisi masyarakat yang berdaya, sedangkan dari bina ruhiyah dapat disebut berhasil dengan keaktifan warga binaan mengikuti pengajian rutin yang diadakan pendamping dan telah rutin mengeluarkan sedekah bahkan sudah ada yang menjadi wali bagi anak yatim di lingkungannya. Kedua hal ini yang menjadi tujuan BAZNAS Kabupaten Sukabumi karena tolok ukur falah (keberhasilan) bukan hanya dari segi materi semata namun lebih dari itu sisi spiritual jauh lebih penting untuk diperkokoh.

\section{REFERENSI}

Ahsan, A. (2009). Laporan Hasil Penelitian Mustahik, Muzakki dan Potensi Pemberdayaan Indonesia. Depok: Lembaga Demografi Fakultas Ekonomi Universitas Indonesia.

Anwar, A. S. H. (2016). Model Pemberdayaan Ekonomi Mustahiq Melalui Zakat. JEAM, XV, 51-61.

Asdiansyuri, U. (2016). ANALISIS PENGARUH PENGELUARAN ZAKAT, INFAK DAN SEDEKAH TERHADAP KESEJAHTERAAN MUZAKKI (STUDI PADA BAZNAS DI KABUPATEN LOMBOK BARAT). International Journal of Social and Local Economic Governance, 2(1), 23-31. https://doi.org/10.21776/ub.ijleg.2016.002.01.3
Dewi. (2017). UNTUK PEMBERDAYAAN KESEJAHTERAAN MUSTAHIQ ( STUDI KASUS PADA LAZIS NU KABUPATEN BANYUMAS ) Dewi. JPA, 18(2), 257-289.

Efendi, M. (2017). Pengelolaan Zakat Produktif Berwawasan Kewirausahaan Sosial dalam Pengentasan Kemiskinan Di Indonesia. AlAhkam, 2(1), 21-37.

Effendi, J., \& Wirawan. (2013). PEMBERDAYAAN MASYARAKAT PENGUSAHA KECIL MELALUI DANA ZAKAT, INFAQ, DAN SEDEKAH (ZIS): Studi Kasus Program Masyarakat Mandiri Dompet Dhuafa terhadap Komunitas Pengrajin Tahu di Kampung Iwul, Kecamatan Parung, Kabupaten Bogor. AlMuzara'ah, 1(2), 161-174. https://doi.org/10.29244/jam.1.2.161-174

Fakhruddin. (2011). MEMBUMIKAN ZAKAT: DARI DARI TA'ABBUDI MENUJU TA'AQQULI Fakhruddin. Jurisdictie, Jurnal Hukum Dan Syariah, 2(1), 95-102.

Farida, A. (2019). Strategi pemberdayaan mustahik di lazismu masjid mujahidin bandung. Jurnal Multikultural \& Multireligius, 17(2), 532-554.

Hamzah. (2015). Pemberdayaan Mustahiq, Zakat Menuju Kemandirian Usaha, Kasus di Kabupaten Bogor Jawa Barat. IPB Bogor.

Herlan. (2017). Wawancara dengan Koordinator Program BUMI BAZNAS Kabupaten Sukabumi. Sukabumi.

Khatimah, H., \& Nuradi. (2020a). Optimalisasi Zakat Melalui Pemberdayaan Muzakki. Rayah AlIslam, 4(2), 244-256. https://doi.org/10.37274/rais.v4i02.90

Khatimah, H., \& Nuradi. (2020b). PEMBERDAYAAN DAN PENINGKATAN KEMANDIRIAN MUSTAHIQ MENJADI MUZAKKI. LAA MAISYIR, 7(2), 1-16.

Komariah, O., \& Damayanti, N. (2015). Zakat Produktif dan Kemandirian Mustahik. Jurnal Islaminomic, 6(2), 79-95.

Maghfiroh, S. (2013). Model Manajemen Strategis Pemberdayaan Ekonomi Umat Melalui Zakat,Infak, Sedekah. Jurnal Ekonomi Dan Hukum Islam, 3(2), 94-116.

Mursyidah, A. (2019). Analisis Indikator Kinerja Zakat Community Development Dalam Rangka Pemberdayaan Mustahik Produktif. Islamic Economic Journal, 5(1), 117-142. 
Jurnal Ilmiah Ekonomi Islam, 7(01), 2021, 33

Nugraha, A. (2009). Pengembangan Masyarakat Pembangunan Melalui Pendampingan Sosial Dalam Konsep Pemberdayaan Di Bidang Ekonomi. Jurnal Ekonomi Modernisasi, 5, 10.

Nugrahani, I. R., \& Mulyawisdawati, R. A. (2019). Peran Zakat Produktif dalam Pemberdayaan Ekonomi Mustahiq ( Studi Kasus Lembaga Amil Zakat Dompet Dhuafa Republika Yogyakarta 2017 ). Jurnal Ekonomi Syariah Indonesia, IX(1), 30-41.

Prahest, D. D., \& Putri, P. P. (2018). Pemberdayaan Usaha Kecil dan Mikro melalui. Ilmu Dakwah: Academic Journal for Homiletic Studies, 12(1), 141-160.

https://doi.org/10.15575/idajhs.v12i.190
Riyadi, A. (2014). Manajemen Pengelolaan Zakat Produktif dalam Perspektif BANK islam. Iqtishadia, 7(2), 335-356.

Sukabumi, B. K. (2014). Laporan Tahunan BAZNAS Kab. Sukabumi Tahun 2014 Periode 2009-2014. Sukabumi: BAZNAS Kab. Sukabumi.

Sutarji, A. (2017). Wawancara dengan pendamping program BUMI BAZNAS Kabupaten Sukabumi. Sukabumi.

Wibisono, Y. (2017). Kinerja dan Proses Kemiskinan. Dialektika Jurnal Kebijakan Publik Republika.

Widiastuti, T., \& Rosyidi, S. (2015). MODEL PENDAYAGUNAAN ZAKAT PRODUKTIF OLEH LEMBAGA ZAKAT. JEBIS, $1(1), 89-$ 102. 